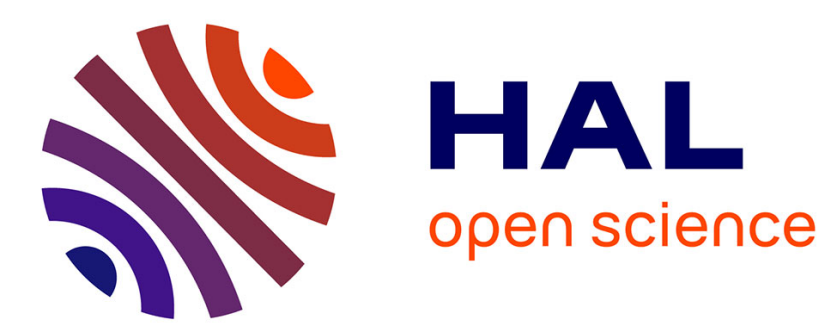

\title{
BRILLOUIN SCATTERING STUDY OF PHASE TRANSITIONS IN p-POLYPHENYLS
}

\author{
C. Ecolivet, B. Toudic, M. Sanquer
}

\section{To cite this version:}

C. Ecolivet, B. Toudic, M. Sanquer. BRILLOUIN SCATTERING STUDY OF PHASE TRANSITIONS IN p-POLYPHENYLS. Journal de Physique Colloques, 1981, 42 (C6), pp.C6-779-C6-781. 10.1051/jphyscol:19816230 . jpa-00221315

\section{HAL Id: jpa-00221315 https://hal.science/jpa-00221315}

Submitted on 1 Jan 1981

HAL is a multi-disciplinary open access archive for the deposit and dissemination of scientific research documents, whether they are published or not. The documents may come from teaching and research institutions in France or abroad, or from public or private research centers.
L'archive ouverte pluridisciplinaire HAL, est destinée au dépôt et à la diffusion de documents scientifiques de niveau recherche, publiés ou non, émanant des établissements d'enseignement et de recherche français ou étrangers, des laboratoires publics ou privés. 


\section{BRILLOUIN SCATTERING STUDY OF PHASE TRANSITIONS IN P-POLYPHENYLS}

C. Ecolivet, B. Toudic and M. Sanquer

Groupe de Physique cristalline, E.R.A. au C.N.R.S. n070015, Université de Rennes, Carpus de Beaulieu, 35042 Rennes Cedex, France

Abstract A Brillouin scattering study of the various phase transitions in p-polyphenyls reveals different kinds of elastic anomalies depending on the nature of these transitions.

INTRODUCTION The first elements of the p-polyphenyls series undergo phase transitions through a change of their molecular conformation. This change happens by an antiferrodistorsive rotation of aromatic rings about the molecular long axis, which effect is the stabilization at low temperatures of a non-planar molecular conformation. Despite theix isomorphism, p-polyphenyls present different kinds of transitions and critical behaviours. We report here some results of a Brillouin scattering investigation of these transitions and their effect on the elastic properties of these crystals.

INCOMMENSURABLE PHASES OF BIPHENYL Biphenyl undergoes a first incommensurate phase transition at $T_{1}=42 \mathrm{~K}$ with modulation vectors along $\vec{a}$ and $\vec{b}$ (4 satellites). This displacive transition is related to a soft mode which happens at the satellites neax the $z$ point $(0,1 / 2,0)$ of the 1 rst Brillouin zone. A partial lock-in transition happens at $\mathbf{T}_{2}=17 \mathrm{~K}$ where the incommensurability along $\vec{a}$ disappears $\left({ }^{1}\right)$.

The major sound velocity anomaly occurs for the quasi longitudinal mode propagating along $\vec{a}$ (figure 1). This kind of elastic anomaly has been observed in many other materials presenting such phases like $\mathrm{K}_{2} \mathrm{~S}_{\mathrm{e}} \mathrm{O}_{4}, \mathrm{Rb}_{2} \mathrm{ZnCl}_{4}$.
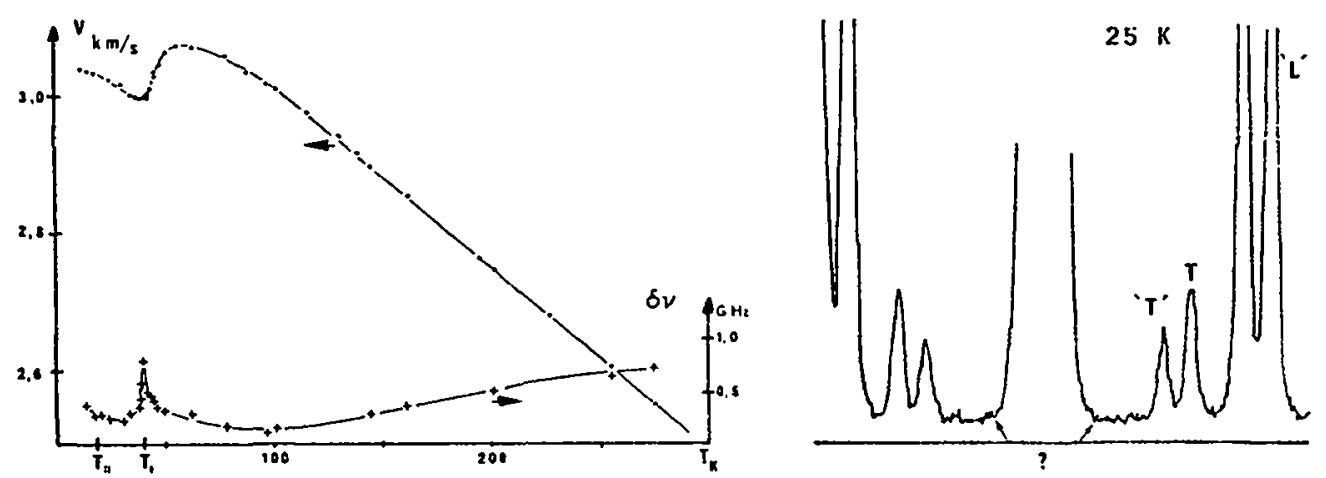

Fig. 1 (left) - Biphenyl quasi-longitudinal sound velocity (upper) and its Brillouin total linewidth lowed versus temperature.

Fig. 2 (right) - Spectrum of biphenyl at $25 \mathrm{~K}$ by phonons propagating along $\vec{a}$. The ar- 
rows at the foot of the Rayleigh indicate the expected location of the phason line, whereas " $L ", " ~ T$ " and $T$ designates the quasi-longitudinal, quasi-transverse and transverse and modes.

As a phason was previously observed by neutron scattering ( ${ }^{1}$ ), we have tried to see it by light scattering. Our experiment failed to find this component and what we can say, if the phason has really a propagation velocity of $1000 \mathrm{~m} / \mathrm{s}$, is that it scatters less than $1 / 10$ of the light scattered by the weakest transverse mode.

IMPROPER FERROELASTIC TRANSITION OF P-TERPHENYL p-terpheny1 undergoes at $193 \mathrm{~K}$ an improper ferroelastic transition labelled $2 / m 1^{\prime} \mathrm{F} \bar{l}$ according to Aizu. This transition is characterized by a superstructure which appears at the $C$ point $(1 / 2,1 / 2,0)$ of the 1xst Brillouin zone leading to the existence of two cristallographically different kinds of domains (Fig.3) depending on the orientation of the molecule central ring $(2)$.

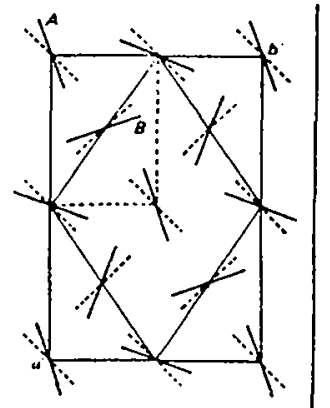

Doma in $\alpha$

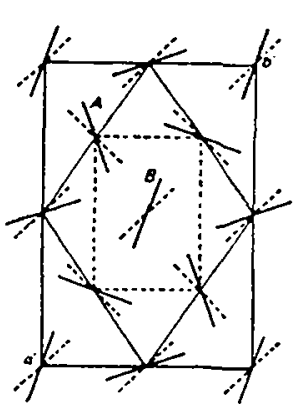

Domain $\beta$
Fig. 3 - Projection on the (001) plane of the central ring orientations in both phases; dashed lines for the high temperature phase and full lines for the low temperature phase.

One of the elastic anomalies created by this order-disorder transition is related to the differentiation of the $|110|$ and $|1 \overline{1} 0|$ directions as it can be seen on the figure above. For one of these directions depending on the domain, central rings are perpendicular to their neighbours whereas along the other direction the angle between central rings is much less. This difference and the presence of several domains in the scattering volume are at the origin of the presence of two distinct and sinultaneous longitudinal Brillouin Iines in the spectrum (Fig. 4).
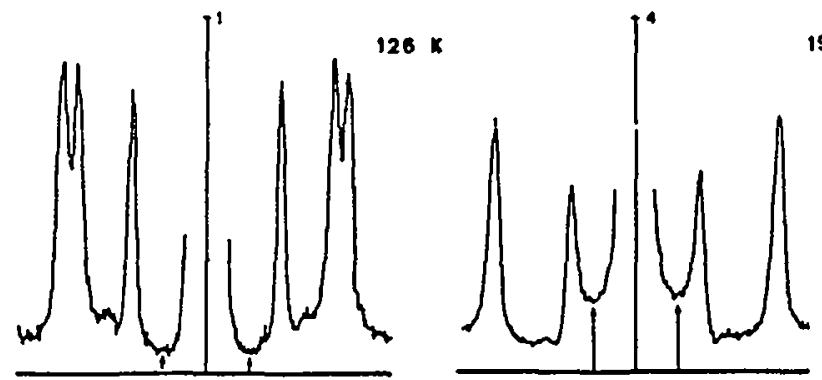

$193 \times$

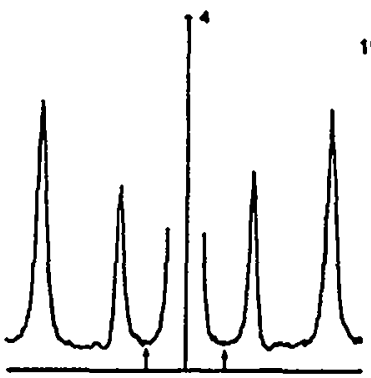

Fig.4 - Right angle Brillouin scattering spectrum in the a(c,c)b geometry at 3 different temperatures showing the "longitudinal" Brillouin Iines (from the next order)and the "transverse" Brillouin lines near the Rayleigh line; notice also a guasi elastic component which goes through a maximum at $T_{C}=193 \mathrm{~K}$. The frequency interval shown is $35.5 \mathrm{GHz}$. 
A fit performed on these spectra between $90 \mathrm{~K}$ and $193 \mathrm{~K}$ shows a $\left(\mathrm{T}_{\mathrm{C}}-\mathrm{T}\right){ }^{0.29}$ variation of this splitting ; it corresponds to the numerical value of 0.30 obtained for the superstructure intensity recorded by neutron scattering ( ${ }^{1}$ ). This value reflects a slight discontinuity of the transition.

THE P-QUATERPHENYL TRANSITION p-quaterphenyl undergoes a transition similar to the $p$-terphenyl in the sense it is also an order-disorder transition between the $p 2 / a$ high temperature phase and probably a $\mathrm{P}-\overline{1}$ low temperature phase with also coexistence of domains $\left({ }^{3}\right)$. But here two central rings are moving in opposite directions inside each molecule and the difference between the $|110|$ and the $|1 \overline{10}|$ is not as obvious as for p-terphenyl and two different longitudinal Brillouin lines are not observed. Genérally the elastic anomalies are also weaker. The figure 5 shows an anomaly of the "longitudinal" sound velocity recorded along $\vec{a}$ which shows a small change of slope at $T_{c}=240 \mathrm{~K}$; there is no complete explanation for this kind of behaviour, but it is could be due to some relaxation mechanism.

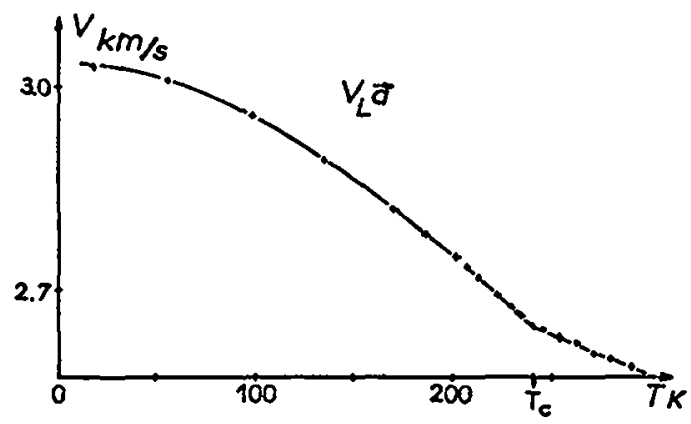

Fig. 5 - Sound velocity of the quasi longitudinal mode propagating along

\section{References}

1. H. CAILLEAU, Thesis Rennes 1981.

2. J.L. BAUdOUR, Y. DELUGEARD, H. CAILleau, Acta Cryst. (1976), B32, 150.

3. J.L. BAUDOUR, Y. DELUGEARD, P. RIVET, Acta Cryst. (1978), B34, 625. 